\title{
3D QSAR Pharmacophore Based Virtual Screening, ADME Analysis and Estimation of MM/GBSA binding Free Energies of Azoles as a Potential Inhibitor of DprE1 for Mycobacterium Tuberculosis
}

Madhavaram Madhavi

Osmania University

Nampally Venkatesh

Osmania University

Tigulla Parthasarathy ( $\nabla$ sarathychem@gmail.com )

osmania university college of science,, $0 U$. https://orcid.org/0000-0001-9498-4896

\section{Research Article}

Keywords: MDR-TB, DprE1, 3D QSAR, Pharmacophore-Based Virtual Screening, MM-GBSA, and ADME analysis.

Posted Date: June 2nd, 2021

DOl: https://doi.org/10.21203/rs.3.rs-571591/v1

License: (c) (1) This work is licensed under a Creative Commons Attribution 4.0 International License.

Read Full License 


\section{Abstract}

Decaprenylphosphoryl - D - ribose - 2 -epimerase (DprE1) is a promising drug target to identify new anti- TB drugs against drug resistant tuberculosis. DprE1 helps in cell wall biosynthesis through Decaprenyl-phosphoryl d-arabinose pathway. Inhibition of DprE1 results in blocking of cell wall biosynthesis, causing death of mycobacterium tuberculosis. In current studies, a set of thirty triazole molecules having antitubercular activity were selected for pharmacophore 3D QSAR studies. The generated common pharmacophore hypothesis (AHRRR.172) consists of one acceptor (A), one hydrophobic $(H)$, and three aromatic rings $(R)$. The resulted pharmacophore model recorded with good statistical results, $R^{2}=0.71, Q^{2}=0.54$ and other parameters $F=45, R M S E=0.41$. This model further investigated to identify pharmacophoric features which are crucial for biological activity. The resultant pharmacophore model was used to screen ZINC chemical database molecules to identify potent lead molecules against DprE1 enzyme. The resultant hit molecules were recorded with dihydroquinonolin 2one and Pyrazolo $[1,5]$ pyramidin 5-one scaffold and this information could be helpful to design new potent anti-tuberculosis agent. Further, these molecules along with co-crystal ligand were utilized for the estimation of physicochemical properties and followed by binding mode analysis.

\section{Introduction}

Tuberculosis is commonly known as TB, it is one of the top killed diseases today and caused by M.tuberculosis [1-2]. As per WHO report, nearly 10 million people infected and 1.4 million people died from tuberculosis in the year of 2019 [3]. India is the highest TB burden country accounting for more than $1 / 4$ global incidence [4-5].

A six months therapy (DOT) was introduced by WHO to treat tuberculosis, which includes administration of four first line drugs (Isoniazid, rifampicin, ethambutol, pyrazinamide) for 2 months, accompanied by administration of two drugs (Isoniazid and rifampicin) for 4 months. This long term treatment of combination of drugs with toxic side effects and poor adherence of patients leads to M. tuberculosis resistant to anti TB drugs called drug resistant TB such as Mu1ti Drug Resistance (MDR) and Extensively Drug Resistance (XDR) TB [6-9]. Multi Drug Resistance TB is form of a drug resistant TB that does no longer replies to at least any one of the first line drugs (especially rifampicin and isoniazid). MDR-TB is treated with administration of second line drugs [10], but this treatment is limited and also expensive. Sometimes additional severe MDR-TB may changes to XDR-TB. According to WHO report, India is one of the countries in the world, which has the highest burden of both tuberculosis and drug resistant tuberculosis. It is reported that nearly 0.5 million people are affected by DR-TB. Therefore, there is a great need to develop novel and effective drugs against tuberculosis [11].

Mycobacterium tuberculosis is unique among prokaryotes. Unlike other prokaryotes, the cel1 wall is made up of lipids, peptidoglycan and arabinogalactan complex (PAM) [12]. This specific property of the cell wall lead to a realization that enzymes involved in the biosynthesis of this structure become attractive potential drug targets to design novel anti TB drugs [13-14]. The D-arabinofuranose is one of the 
important constituent of cell wall biosynthesis. DprE(Decaprenylphosphoryl - D - ribose - 2 - epmerase) is essential for the conversion of ADP to DPA which is precursor of arabinogalactan synthesis in cell wall [15-16]. DprE1 is the enzyme FAD-dependent oxido-reductase while the other enzyme DprE2 depends on NADH reductase. The previous studies suggest that some of the molecules such as benzthiazinones against DprE1 have antibacterial activity without exhibiting TB resistance [17]. This indirectly confirms that enzyme DprE1 is a promising drug target to design new anti- TB drugs [18-22].

In recent years $M$. tuberculosis has attained elevated resistance across drugs [23-28]. Hence, there is a need to establish novel, fast acting and potent anti- microbial drugs with reduced toxicity. The development of novel drugs with XDR-TB, MDR-TB, and latent TB is a primary concern and will help to cut down the chemotherapy [29]. Thereby in this present study, a set of triazole derivatives, which are found to be highly effective for anti-tubercular activity were selected for 3D QSAR and pharmacophore based virtual screening. The resultant pharmacophore model reveals that the pharmacophoric features, which are crucial significant functions for ligand binding.

\section{Materials And Methods}

\subsection{Data set selection and preparation for analysis}

For the computational analysis, a total of thirty-one triazole derivatives' against $\mathrm{M}$. tuberculosis were selected from literature by considering a wide range of activity (suplamentary table S1)[30]. The pharmacological activity of these compounds was expressed in $\mathrm{IC}_{50}$ value. To generate a QSAR model, the reported $\mathrm{IC}_{50}$ values were transformed into corresponding $\mathrm{pIC}_{50}$ value by using $\mathrm{pIC}_{50}=-\log \mathrm{IC}_{50}$.

The chemical structures of all the data set molecules were drawn by using $2 \mathrm{D}$ sketcher. All the 2D chemical structures converted into 3D chemical structures during creating a new entry into the project file. The energy optimizations of 3D structures were carried out by using Ligprep module, employing OPLS_ 2005 force field [33]. It includes generation of stereoisomer, neutralization of optical structures and generation of most credible ionization states at target pH 7.0 \pm 2.0 [31]. The molecules were then subjected to ConfGen with OPLS_2005 force field to get various conformations for each molecule.

\subsection{Generation of Pharmacopore sites}

The energy minimized chemical structures along with biological activity (i.e. $\mathrm{plC}_{50}$ ) are imported into PHASE module to get a validated 3D QSAR model. PHASE module makes available inbuilt generation of pharmacophores, such as Acceptor - A, Donor -D, Hydrophobic - H, Positive and Negative - P/N and Aromatic Rings - R. In order to find common pharmacophores for all active ligands "Develop Common Pharmacophore Hypothesis" was used by selecting a maximum number of pharmacophore sites five. Consequently, nine variant pharmacophores have appeared. Basically, the resulting pharmacophore hypothesis are scored to get the best alignment pharmacophore hypothesis by using automatic default parameter such as vector, site and volume scores above 1.0 and RMSD value under $1.7 \mathrm{~A}^{0}$ in the Phase 
module. The quality of pharmacophore model depends on the highest survival score or survival-inactive score. The survival score exhibited as in the following equation

$\mathrm{S}=\mathrm{W}_{\text {site }} \mathrm{S}_{\text {site }}+\mathrm{W}_{\mathrm{vec}} \mathrm{S}_{\mathrm{vec}}+\mathrm{W}_{\mathrm{vo} 1} \mathrm{~S}_{\mathrm{vo} 1}+\mathrm{W}_{\mathrm{se1}} \mathrm{S}_{\mathrm{se} 1}+\mathrm{W}_{\text {rew }}^{\mathrm{m}}$

Where, $\mathrm{W}$ and $\mathrm{S}$ symbolize volume and score; $\mathrm{S}_{\text {site }}$ imply alignment score; $\mathrm{S}_{\text {vec }}$ represents vector score; $\mathrm{S}_{\mathrm{vo} 1}$ imply volume score; $\mathrm{S}_{\mathrm{se} 1}$ represents selectivity score and $\mathrm{W}^{\mathrm{m}}{ }_{\text {rew }}=$ reward weights defined by $\mathrm{m}-\mathrm{I}$ (where, $\mathrm{m}$ outline the number of actives that suite to hypothesis) [32].

PHASE is a highly flexible system, it provides two alternatives for the 3D QSAR model development i.e., Pharmacophore based QSAR model, whereas another one is Atom based QSAR model. During this work, we have chosen atom based 3D QSAR model which is more suitable for explaining the structural activity relationship of database ligands having similar scaffolds. In this method each atom of the molecule is assigned as a particular molecular feature such as hydrogen-bond donors (D), hydrogen bond acceptors $(A)$, negative and positive ionic $(N / P)$, electron withdrawing $(w)$ and miscellaneous $(X)$. The atom based QSAR model was generated by applying a statistical technique called partial least squares (PLS) analysis value five and grid space $1 A^{0}$. The obtained atom based pharmacophore model was further evaluated via flowing some statistical measures i.e. $\mathrm{R}^{2}=$ correlation coefficient; $\mathrm{Q}^{2}=$ predicted activities; $\mathrm{SD}=$ standard deviation; $\mathrm{F}$ = overall significance of Model; RMSE = root mean square error; Pearson $\mathrm{R}$ value; number of PLS factors and stability. Further the PLS factor with low RMSE value was selected among all the PLS factors.

\subsection{Evaluation of model generation}

The development of 3D QSAR model is a crucial step to establish a statistical significant relationship between the target property and descriptors. QSAR model was generated by using the partial least square method (PLS) to escape false outcomes. The fined common pharmacophore among the active ligands, a set of desired variant list selected with the option create site as default in Phase module [34]. As a result two variants with maximum hypothesis AHRRR, AAHRR are formed from list of nine variant combinations i.e., AAAHH, AAAHR, AAARR, AAHHR, AAHRR, AARRR, AHHRR and AHRRR, HHRRR. To get best pharmacophore model, all nine variants are scored by applying the automatic default parameter of PHASE module. The resulted best hypothesis (AHRRR) is associated with one hydrogen bond acceptor; A (displayed with a pink color sphere), one hydrophobic; $\mathrm{H}$ (displayed with green color sphere) and three aromatic groups; $\mathrm{R}$ (displayed with an orange color sphere) (Fig. 2). The angle and distances between the spheres of common hypotheses are arranged in Table 1. 
Table 1

The distance and angle between spheres of common pharmacophore

\begin{tabular}{|c|c|c|c|c|}
\hline \multicolumn{5}{|c|}{ Angle between the common pharmacophore sites } \\
\hline Entries & Site-1 & Site-2 & Site-3 & Angle in $\mathrm{A}^{0}$ \\
\hline 1 & $\mathrm{H} 4$ & A3 & R6 & 168.4 \\
\hline 2 & $\mathrm{H} 4$ & A3 & R7 & 1.0 \\
\hline 3 & $\mathrm{H} 4$ & A3 & $\mathrm{R} 8$ & 153.6 \\
\hline 4 & R6 & A3 & R7 & 167.4 \\
\hline 5 & R6 & A3 & $\mathrm{R} 8$ & 21.9 \\
\hline 6 & R7 & A3 & R8 & 153.0 \\
\hline 7 & A3 & $\mathrm{H} 4$ & R6 & 4.2 \\
\hline 8 & A3 & $\mathrm{H} 4$ & R7 & 0.9 \\
\hline 9 & A3 & $\mathrm{H} 4$ & $\mathrm{R} 8$ & 14.8 \\
\hline 10 & R6 & $\mathrm{H} 4$ & R7 & 3.3 \\
\hline 11 & R6 & $\mathrm{H} 4$ & R8 & 12.9 \\
\hline 12 & R7 & $\mathrm{H} 4$ & R8 & 14.3 \\
\hline 13 & A3 & R6 & $\mathrm{H} 4$ & 7.4 \\
\hline 14 & A3 & R6 & R7 & 5.7 \\
\hline 15 & A3 & R6 & R8 & 141.8 \\
\hline 16 & $\mathrm{H} 4$ & R6 & R7 & 1.7 \\
\hline 17 & $\mathrm{H} 4$ & R6 & R8 & 140.0 \\
\hline 18 & R7 & R6 & R8 & 140.5 \\
\hline 19 & A3 & R7 & $\mathrm{H} 4$ & 178.0 \\
\hline 20 & A3 & R7 & R6 & 6.9 \\
\hline 21 & A3 & R7 & R8 & 19.7 \\
\hline 22 & $\mathrm{H} 4$ & R7 & R6 & 175.0 \\
\hline 23 & $\mathrm{H} 4$ & R7 & R8 & 161.3 \\
\hline 24 & R6 & R7 & R8 & 16.6 \\
\hline 25 & A3 & R8 & $\mathrm{H} 4$ & 11.6 \\
\hline
\end{tabular}




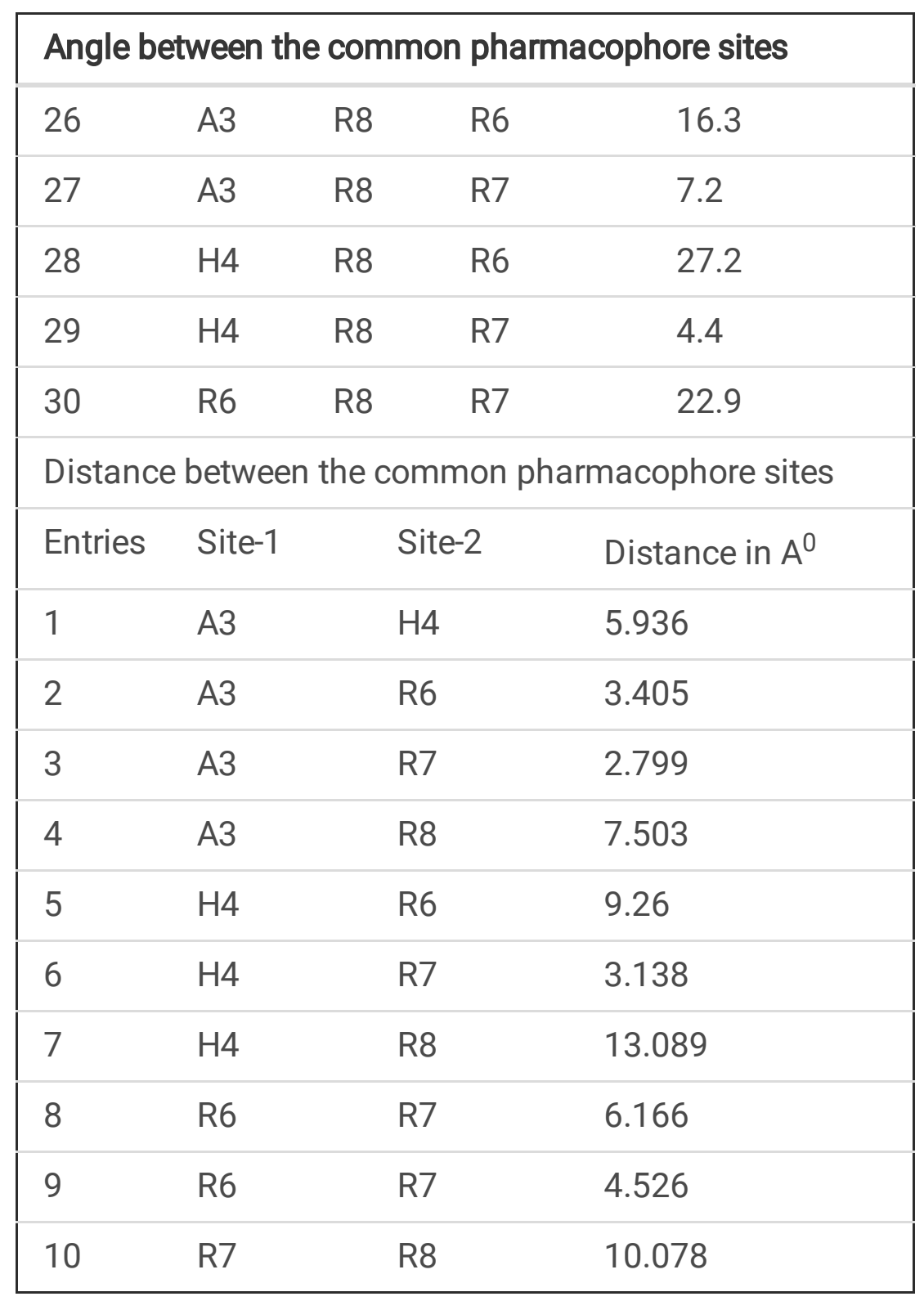


Table 2

The various parameters of the training and test set ligands.

\begin{tabular}{|c|c|c|c|c|c|}
\hline C.N & Exp. A (plC50) & QSAR set & Pre. A (plC50) & F. Score & Pharm Set \\
\hline M1 & 5.769 & training & 5.25 & 2.05 & moderate \\
\hline M2 & 5.619 & training & 5.59 & 2.42 & moderate \\
\hline M3 & 5.455 & test & 5.64 & 2.53 & moderate \\
\hline M4 & 5.619 & test & 5.3 & 2.28 & moderate \\
\hline M5 & 5.494 & training & 5.62 & 2.53 & moderate \\
\hline M6 & 5.958 & training & 5.78 & 2.87 & moderate \\
\hline M7 & 5.619 & test & 5.7 & 2.8 & moderate \\
\hline M8 & 5.6 & training & 5.21 & 2.25 & moderate \\
\hline M9 & 5.52 & test & 5.71 & 2.88 & moderate \\
\hline M10 & 5.1 & training & 5.2 & 2.25 & moderate \\
\hline M11 & 5.443 & training & 5.87 & 2.95 & moderate \\
\hline M12 & 5.585 & training & 5.5 & 2.65 & moderate \\
\hline M13 & 6.154 & test & 5.8 & 3 & active \\
\hline M14 & 5.537 & training & 5.74 & 2.96 & moderate \\
\hline M15 & 6.301 & test & 5.79 & 2.99 & active \\
\hline M16 & 4 & training & 4.03 & 2.02 & inactive \\
\hline M17 & 5.08 & training & 5.22 & 2.35 & moderate \\
\hline M18 & 4.27 & test & 5.12 & 2 & inactive \\
\hline M19 & 4.575 & training & 5.22 & 2.41 & inactive \\
\hline M20 & 4.364 & test & 5.12 & 2 & inactive \\
\hline M21 & 6.096 & training & 6.02 & 2.92 & active \\
\hline M22 & 5.657 & training & 5.82 & 2.85 & moderate \\
\hline M23 & 6.698 & training & 5.96 & 2.97 & active \\
\hline M24 & 5.619 & training & 5.93 & 2.96 & moderate \\
\hline M25 & 5.657 & test & 5.59 & 2.22 & moderate \\
\hline M26 & 5.585 & training & 5.72 & 2.39 & moderate \\
\hline M27 & 6.096 & training & 5.83 & 2.47 & active \\
\hline
\end{tabular}




\begin{tabular}{|llllll|}
\hline C.N & Exp. A (pIC50) & QSAR set & Pre. A (pIC50) & F. Score & Pharm Set \\
\hline M28 & 5.657 & test & 5.71 & 2.44 & moderate \\
M29 & 6.04 & test & 5.83 & 2.46 & active \\
M30 & 5.585 & training & 5.69 & 2.08 & moderate \\
M31 & 4.602 & training & 4.49 & 2.17 & inactive \\
$\begin{array}{l}\text { C.N: Compound Name; Exp. A: Experimental Activity (plC50); Pre. A: Predicted Activity (pIC50); F. } \\
\text { Score: Fitness Score }\end{array}$ & & & \\
\hline
\end{tabular}

\subsection{Virtual Screening}

Virtual screening is the largest source of novel lead over the last fifteen years, which is mainly in terms of cost effect less and probability of finding the most appropriate novel hits. The virtual screening workflow utilizes the "Glide module" to search best fit molecule (best pose) [35-36]. Glide allows the scientist to screen the dataset molecule in three different ways of the docking protocol, namely High throughput virtual screening (HTVS), Standard precision (SP) and Extra precision (XP) mode [37-39]. The force field employed during docking stimulations is OPLS_2005.

\subsection{Protein Preparation}

In order to use protein for docking, the structure file of DprE1 in a complex with CT319 was downloaded from the protein data bank with resolution $2.4 \mathrm{~A}^{\circ}$ (PDB ID 4FDO) [52]. The first step in keeping with the requirement, the protein is prepared by using Protein Preparation Wizard workflow [40-41]. The preparation includes adding hydrogen in physiological $\mathrm{pH}$ value, removal of water molecules beyond $5 \mathrm{~A}^{0}$ from the group that are not concerned in ligand binding, preprocessing and energy minimization in the selected force field (OPLS2005 and RMSD of $0.30 \AA$ ). After the energy minimization, the receptor active sites are identified by choosing a co-crystal ligand.

\subsection{Grid generation}

Grid generation is a very crucial step in molecular docking to expect the ligand binds. The Grid was generated by selecting the co-crystal ligand in ligand binding domain, which generates the grid containers and changed it with the studied ligands in the course of the method of docking [42].

\subsection{MM/GBSA calculations}

The binding free energies of a docked complex were determined by using Prime MM/GBSA (Molecular Mechanics/ Generalized Born Surface Area) method [43-49]. This comprises OPLS-2005 force field and rotamer search algorithm. The change in the binding free energy of docked complex i.e. $\Delta \mathrm{G}_{\text {bind }}$ can be calculated with the following equation

$\Delta G_{\text {bind }}=E_{\text {complex }}-\left(E_{\text {protein }}+E_{\text {ligand }}\right)$ 
Here, the term $\Delta \mathrm{G}_{\text {bind }}$ defines ligand binding energy with receptor; $\mathrm{E}_{\text {complex }}$ define energy of complex after docking; $E_{\text {protein }}$ defines energy of receptor before docking; $E_{\text {ligand }}$ defines energy of ligand.

\section{Results And Discussion}

A set of thirty-one data set molecules having triazole moiety was selected and divided into two training and test set consisting of twenty-one and nine molecules respectively to get the best alignment pharmacophore model by using a default parameter "maximum number of sites" 5 and "minimum number of sites" 3 . The ligand molecules are divide into active and inactive molecules based on an activity threshold value, the molecules which has $\mathrm{plC}_{50}$ more than 6.0 considered as an active molecule, on the other hand, the molecules which has $\mathrm{pIC}_{50}$ less than or equal to 4.8 considered as inactive molecules and the molecules which has $\mathrm{plC}_{50}$ in-between 6.0 to 4.8 is considered as moderate to get best pharmacophore model. The generated model is validated by different statistical parameters such as $\mathrm{R}^{2}$, $\mathrm{Q}^{2}$, RMSE, SD, F and Pearson $\mathrm{R}$ value. These are measured to inspect the strength of the pharmacophore model and the model with PLS value identified to be best. The best hypothesis associates with a Low Root Mean Square Error (RMSE) value of 0.418 , higher the stability value of (S) 0.3628 , higher the value of (F) 45 and lower the value of $\mathrm{P}$ (2.743e-006). The model AHRRR 1 also recorded with high predictive correlation value of $0.5492\left(Q^{2}\right)$, a good correlation coefficient value of $0.712\left(R^{2}\right)$ along a high Pearson $R$ value of 0.8899 specifies that there is a correlation between actual and predicted biological activity. The difference between correlation coefficient $R^{2}$ and predictive correlation valueQ $Q^{2}$ is less than $0.3\left(R^{2}-Q^{2}=\right.$ 0.165 ), this low value suggested that the obtained model is accurate and reliable [50-51](Table 3). Figure 2 illustrated that the hydrogen bond acceptor A3 (pink color sphere) mapped with oxygen atom which is located between triazole and benzene ring, whereas the hydrophobic $\mathrm{H} 4$ (green color sphere) mapped with an atom at para position of benzene ring present on the fourth position of triazole. The aromatic rings R6, R7 and R8 (orange color sphere) are mapped with all three rings of ligand molecules. The graph of experimental v's predicted biological activity (in terms of $\mathrm{IC}_{50}$ ) of anti-tubercular inhibitors is given in Fig. 1. All the active and inactive molecules are aligned to map common pharmacophoric features which is a crucial step in the development of pharmacophore model. The alignment of a fittest molecule to map common pharmacophore is shown in Fig. 2. Further, these are treated to generate 3D QSAR model through applying test and training set molecules (Table-2).

Table 3

Summary of phase statistical model

\begin{tabular}{|lccccccc|}
\hline S.N. & $\mathbf{R}^{2}$ & $\mathbf{F}$ & $\mathbf{Q}^{2}$ & SD & $\mathbf{P}$ & RMSE & Pearson R \\
\hline AHRRR.172 & 0.7142 & 45 & 0.5496 & 0.3277 & $2.43 e .006$ & 0.417 & 0.8899 \\
\hline $\begin{array}{l}\text { R }^{2} \text { = correlation coefficient; } \\
\text { of Model; RMSE = root mean square error; }\end{array}$ & Pearson son R value; number of PLS factors and stability. \\
\hline
\end{tabular}


Due to technical limitations, table 4 is only available as a download in the Supplemental Files section.

Table 5

Docking results of top 15 molecules.

\begin{tabular}{|lllll|}
\hline Compound & Docking Score & XP Score & Glide emodel & B.A kcal/mole \\
\hline S1 & -9.4 & -11.4 & -91.9 & -49.7 \\
\hline S3 & -9.3 & -11.2 & -85.1 & -70.2 \\
\hline S4 & -10.2 & -11.2 & -89.6 & -46.7 \\
\hline S5 & -10.0 & -11.2 & -81.9 & -67.8 \\
\hline S6 & -9.5 & -11.0 & -90.8 & -81.9 \\
\hline S7 & -10.3 & -11.0 & -101.8 & -73.7 \\
\hline S8 & -10.7 & -10.9 & -58.2 & -78.7 \\
\hline S9 & -10.2 & -10.6 & -91.4 & -75.9 \\
\hline S10 & -10.5 & -11.5 & -85.4 & -80.3 \\
\hline S11 & -10.4 & -11.1 & -91.3 & -74.9 \\
\hline S12 & -9.3 & -10.5 & -71.3 & -70.3 \\
\hline S13 & -9.7 & -10.5 & -64.8 & -66.3 \\
\hline S14 & -9.7 & -10.4 & -86.9 & -91.4 \\
\hline S15 & -10.12 & -10.2 & -86.8 & -79.0 \\
\hline Co-crystal & -7.7 & -10.3 & -63.4 & -75.7 \\
\hline Ual inspeCtion Of Atom-based 3D QSAR Model & -7.7 & -56.2 & -48.3 \\
\hline
\end{tabular}

The results of 3D QSAR model were visually inspected to identify ligand features that contribute to enhance or diminish the activity. These features are crucial for the interaction of the ligand molecule and its target enzyme. According to the sign of their co-efficient value, the regression map are color coded.

The blue color indicates that most favorable significant biological activity and the red color indicates the unfavorable biological activity. The blue color cubes suggest that increase in activity while red color cube indicates adecrease in activity. In order to identify the chemical features of ligand molecules, whether they are enhance or diminish the biological activity determined by visual inspection of 3D QSAR model. This information provides a piece of evidence for convince and non-convince groups at a specific position on ligand molecule. 


\subsection{Visualization of an active molecule}

The 3D visualization of compound M15 (active; 5.79) and compound M16 (inactive; 4.03) were carried out to attempt more insight into Structural Activity Relationship (SAR) to describe a biological activity. The pictorial representation of molecule M15 and M16 is displayed in Fig. 3. The hydrophobicity feature of molecule M15 and molecule M16, which is obtained by 3D QSAR model, is represented in Fig. 3. It reveals that the presence of blue color cubes around hydrophobic feature at para position to benzene reveals more favorable for activity. Similarly, the presence of hydrophobic groups except for para position on benzene reveals that unfavorable for activity. It advises that as the hydrophobic substituent is added tothephenyl ring and inhibitory activity of the ligand increases.

The electron withdrawing field prediction that had been obtained from atom based QSAR model applied most active (M15) and inactive ligands (M16). The pictorial representation of Fig. 3 demonstrates that the presence of red color cubes around the group ' $\mathrm{NO}_{2}$ ' indicates the unfavorable for biological activity. The presence of electron withdrawing substituents indicates a decrease in biological activity.

\subsection{Virtual Screening}

The resulted 3D QSAR model (AHRRR) was employed as a 3D quarry to screen ZINC database molecules to identify novel lead molecules [53]. The screening resulted in 22,271 molecules and utilized for virtual screening workflow. It includes HTVS (high throughput virtual screening), SP (standard precision) and XP (extra precision) modes. Initially, these molecules were screened by utilizinghigh throughput virtua1 screening (HTVS) against the DprE1 enzyme with a default parameter without any constraints. Further, these molecules were exposed to Glide SP mode followed by Glide XP mode. As a result, 31 molecules with a good Glide score were recorded. The obtained virtual hits are subjected to further analysis. The GLIDE (Glide-Based Ligand Docking with Energetics) is an automated docking program,which is used to explore the interaction between the ligand and receptor molecule. The ligand interaction tool of Schrödinger was utilized to investigate the intermolecular interaction between the ligand and receptor molecule.

\subsection{Binding free energy estimation}

The docked complexes obtained as virtual hits along with receptor co-crystal ligand were exposed to MM/GBSA calculations to estimate relative binding free energy.The binding energy values are ranging from -46.27 to $-91.45 \mathrm{kcal} /$ mole. The binding free energy of co-crystal ligand with a receptor is -52.67 $\mathrm{kcal} / \mathrm{mole}$. The binding affinity of a co-crystal ligand is fixed as a cutoff value to screen the compound. As a result,fifteen molecules having good binding free energy and these molecules are utilized for further analysis. The molecules which are recorded above the cutoff value and their estimated binding energies 
are depicted in Table $\mathbf{5}$. Table-5 pointedout that they all resulted in fifteen molecules compriseofhydroquinoline - 2one and pyrimidine 5-one moiety.

\subsection{ADME properties}

The estimation of ADME properties is an important indicator for the development of novel drug molecules. All the Unfavorable properties help to eliminate the drug molecule in the process of drug development. The molecules which are resulted from virtual screening are screened by utilizing QuickProp module of the Schrodinger suit. The calculated physicochemical properties such as $\mathrm{H}$-donors, $\mathrm{H}$-acceptors, molecular weight, Plog S, QplogPoct, number of violations related to Lipinski rule of five and three [54] are listed in Table-4. The QuickProp results indicate that the molecules S3-S10 and S14 were recorded with desirable physicochemical properties; however the molecules S8 and S14 were recorded with $100 \%$ human oral absorption value. The molecules S1, S2, S11 to S13 and S15 were recorded with good binding affinity even though they are recorded undesirable physicochemical properties. The molecules which are recorded with desirable physicochemical properties were selected for further analysis.

\subsection{Binding mode investigation}

In the current study, determination of active site was carried by choosing co-crystal ligand and the residues which are present at the active site were shown in figure-4. The co-crystal ligand within the protein molecule was extracted and re-docked to get awareness into on binding pattern of ligand at the active site. For the validation of docking accuracy, the RMSD value is calculated between the experimental conformation and re-docked conformation of co-crystal ligand at the active site of the target protein.The co-crystal ligand forms two H-bonds with amino acid residues Gly117 and Tyr60 with a bond distance of $2.14 A^{0}, 1.681 A^{0}$ respectively. Based on knowledge of Glide energy, binding affinity, hydrogen bond interactions and physicochemical properties, four molecules were selected as hit molecules and utilized for binding mode analysis. The binding mode analysis of all four hit molecules are shown in Fig. 5. Results of binding mode analysis indicate that the molecule S8 (ZINC44890235) forms H-bonding interactions between the $\mathrm{O}$ atom of methoxy-methyl group and - $\mathrm{NH}$ of Gly117, $\mathrm{O}$ atom of carboxamide and $-\mathrm{OH}$ group of Tyr60 with a bond distance $1.96 \mathrm{~A}^{0}$ and $2.17 \mathrm{~A}^{0}$ respectively same as co-crystal ligand. In addition to this,the molecule $\mathrm{S} 8$ also forms $\mathrm{H}$-bond interaction with amino acid Arg58 and Pi-Pi interactions amino acid Lys 418 with a bond distance of $2.36 \mathrm{~A}^{0}$ and $5.01 \mathrm{~A}^{0}$ respectively. The molecule $S 9$ (ZINC58156954) forms three H-bond interactions with active site amino acids Hid136, Tyr415 and Lys418 with bond distance $2.10 \mathrm{~A}^{0}, 1.85 \mathrm{~A}^{0}$ and $1.96 \mathrm{~A}^{0}$ respectively. The figure- 6 indicates the binding mode of molecule S14 (ZINC35685029). The binding mode analysis of molecule S10 (ZINC44920132) is similar to molecule S8. The molecule S10 forms three hydrogen bonds with amino acids Gly117, Arg58 and Tyr60 with bond distances $1.93 A^{0}, 2.40 A^{0}$ and $2.20 A^{0}$ respectively. The molecule $\mathrm{S} 10$ also forms $\mathrm{Pi}-\mathrm{Pi}$ interactions with amino acid Lys $418 A^{0}$. However, the molecule S14 recorded with three $\mathrm{H}$-bonds between the $O$ atoms of methoxy group with amino acid Cys 129 with bond distance $2.02 A^{0}$, the 0 atom of the pyrimidine 5 - one and amino acid Arg 58 with bond distance $2.05 \mathrm{~A}^{0}$. In addition to this, it also forms $\mathrm{H}$ - 
bond with amino acid Tyr60 with bond distance $2.15 \mathrm{~A}^{0}$ and Pi-Pi interactions with Lys418.The binding mode analysis of all top hit molecules along with co-crystal ligand at the active site shows in Fig. 6 . The binding mode analysis of compounds S3 to S7 shwon in suplamentaryfigure S1.

\section{Conclusion}

Mycobacterium tuberculosis has attained elevated resistance across drugs. Hence there is a need to develop potent anti- microbial drugs with reduced toxicity. In the current study, 3D QSAR model was developed to investigate the pharmacophoric features which are crucial for biological activity. The generated common pharmacophorehypothesis (AHRRR.172) consists of one acceptor-A, one

hydrophobic-H and three aromatic rings $-\mathrm{R}$. These are essential features for ligand binding. The generated 3D QSAR model was found to be recorded with good statistical results with $R^{2}=0.71, Q^{2}=0.54$ and other parameters $F=45, R M S E=0.41$. The difference between $R^{2}$ and $Q^{2}$ is very low and this indicates that the obtained model is accurate and reliable. Visual examination of resulted 3D QSAR model, within the context of the foremost active and least active molecule, explains the structural features responsible for biological activity against DprE1 enzyme. The obtained five-point pharmacophoremodel was used to screen zinc chemical database molecules to identify potent lead molecules against DprE1 enzyme. The resultant molecules recorded with dihydroquinonolin 2-one and Pyrazolo[1,5] pyramidin 5-one scaffold areutilized for the estimation of physicochemical properties and followed by binding mode analysis. The QuikProp study reveals that all hit molecules are associated with good pharmacokinetic properties and considered as prospective drug candidates for future research.

\section{Declarations}

\section{Acknowledgments}

One of the authors M. M. is thankful to the UGC-RGNFD,New Delhi, for financial assistance. The authors M.M, N.V and T.P are thankful to the head of chemistry and the principal, University College of science, Osmania University, Tarnaka Hyderabad for providing facilities to carry out present work.

Funding information:This study is financially supported by UGC-RGNFD.

Conflicts of interest The authors declare that there is no competing of interests.

\section{References}

1. De Souza MVN. Current status and future prospects for new therapies for pulmonary tuberculosis. Curr Opin Pulm Med. 2006;12 (3):167-171. doi:10.1097/01.mcp.0000219264.42686.c9 
2. Coelho TS, Cantos JB, Bispo MLF, et al. In vitro anti-mycobacterial activity of (E)-N'-(monosubstitutedbenzylidene) isonicotinohydrazide derivatives against isoniazidresistant strains. Infect Dis Rep. 2012;4(1):49-51. doi:10.4081/idr.2012.e13

3. WHO. Global Tuberculosis Report 2020 New data on tuberculosis trends in 202 countries. Who. 2020. https://www.who.int/tb/global-report-2019.

4. DivisionWelfare, C. T. India TB Report 2019. Welfare, Ministry of Health and Family. 2019, p 244.https://tbcindia.gov.in/

5. Kumar P, Saumya KU, Giri R. Identification of peptidomimetic compounds as potential inhibitors against MurA enzyme of Mycobacterium tuberculosis. J Biomol Struct Dyn. 2019;38(17):4997-5013. doi:10.1080/07391102.2019.1696231

6. Agyeman AA, Ofori-Asenso R. Tuberculosis-an overview. J Public Heal Emerg. 2017;1(3):1-7. doi:10.21037/jphe.2016.12.08

7. Smith SE, Ershova J, Vlasova N, et al. Risk factors for acquisition of drug resistance during multidrugresistant tuberculosis treatment, Arkhangelsk Oblast, Russia, 2005-2010. Emerg Infect Dis. 2015;21(6):1002-1011. doi:10.3201/eid2106.141907

8. Gargi T, Shalvi T and Harshad T. Status and challenges for tuberculosis control in India e Stakeholders' perspective.Indian J Tuberc. 2020.doi.org/10.1016/j.jijtb.2020.10.001

9. Falzon D, Gandhi N, Migliori GB, et al. Resistance to fluoroquinolones and second-line injectable drugs: Impact on multidrug-resistant TB outcomes. Eur Respir J. 2013;42(1):156-168.

doi:10.1183/09031936.00134712

10. Cole ST, Riccardi G. New tuberculosis drugs on the horizon. Curr Opin Microbiol. 2011;14(5):570-576. doi:10.1016/j.mib.2011.07.022

11. Zumla A, Nahid P, Cole ST. Advances in the development of new tuberculosis drugs and treatment regimens. Nat Rev Drug Discov. 2013;12(5):388-404. doi:10.1038/nrd4001

12. Brennan PJ. Structure, function, and biogenesis of the cell wall of Mycobacterium tuberculosis. Tuberculosis(Edinb). 2003;83(1-3):91-97. doi:10.1016/S1472-9792(02)00089-6

13. Crick DC, Mahapatra S, Brennan PJ. Biosynthesis of the arabinogalactan-peptidoglycan complex of Mycobacterium tuberculosis. Glycobiology. 2001;11(9):107R-118R.doi.org/10.1093/glycob/11.9.107R

14. Takayama K, Wang C, Besra GS. Pathway to synthesis and processing of mycolic acids in Mycobacterium tuberculosis Clin Microbiol Rev. 2005;18(1):81-101. doi:10.1128/CMR.18.1.81 
15. Wolucka BA. Biosynthesis of $D$-arabinose in mycobacteria - a novel bacterial pathway with implications for antimycobacterial therapy. FEBS J.2008;275(11):2691-2711. doi:10.1111/j.17424658.2008.06395.x

16. Batt SM, Jabeen T, Bhowruth V, Quill L, Lund PA, Eggeling L, Luke J, Fütterer K, Besra GS. Structural Basis of inhibition of mycobacterium tuberculosis DprE1 by benzthiazinone inhibitors.Proc Natl Acad Sci U S A. 2012; 109(28):11354-11359. doi:10.1073/pnas.1205735109

17. Makarov V, Manina G, Mikusova K, Möllmann U, Ryabova O, Saint-Joanis B, Dhar N, Pasca MR, Buroni S, Lucarelli AP, Milano A, De Rossi E, Belanova M, Bobovska A, Dianiskova P, Kordulakova J, Sala C, Fullam E, Schneider P, McKinney JD, Brodin P, Christophe T, Waddell S, Butcher P, Albrethsen J, Rosenkrands I, Brosch R, Nandi V, Bharath S, Gaonkar S, Shandil RK, Balasubramanian V, Balganesh T, Tyagi S, Grosset J, Riccardi G, Cole ST. Benzothiazinones kill Mycobacterium tuberculosis by blocking arabinan synthesis. Science. 2009;324(5928):801-804. doi: 10.1126/science.1171583

18. Yalcin G, Burmaoglu S, Yildiz I, Algul O. Molecular Docking Studies on Fluoro-Substituted Chalcones as Potential DprE1 Enzyme Inhibitors. J. Mol. Struct.2018; 1164: 50-56. doi:10.1126/science.1171583

19. Makarov V, Lechartier B, Zhang M, Neres J, van der Sar AM, Raadsen SA, Hartkoorn RC, Ryabova OB, Vocat A, Decosterd LA, Widmer N, Buclin T, Bitter W, Andries K, Pojer F, Dyson PJ, Cole ST. Towards a new combination therapy for tuberculosis with next generation benzothiazinones. EMBO Mol Med. 2014;6(3):372-384.doi: 10.1002/emmm.201303575

20. Gawad J, Bonde C. Synthesis, Biological Evaluation and Molecular Docking Studies of 6-(4Nitrophenoxy)-1H-Imidazo[4,5-b]Pyridine Derivatives as Novel Antitubercular Agents: Future DprE1 Inhibitors. Chem. Cent. J.2018; 12 (1): 1-11. doi.org/10.1186/s13065-018-0515-1

21. Shirude PS, Shandil R, Sadler C, Naik M, Hosagrahara V, Hameed S, Shinde V, Bathula C, Humnabadkar V, Kumar N, Reddy J, Panduga V, Sharma S, Ambady A, Hegde N, Whiteaker J, McLaughlin RE, Gardner H, Madhavapeddi P, Ramachandran V, Kaur P, Narayan A, Guptha S, Awasthy D, Narayan C, Mahadevaswamy J, Vishwas KG, Ahuja V, Srivastava A, Prabhakar KR, Bharath S, Kale R, Ramaiah M, Choudhury NR, Sambandamurthy VK, Solapure S, lyer PS, Narayanan S, Chatterji M. Azaindoles: noncovalent DprE1 inhibitors from scaffold morphing efforts, kill Mycobacterium tuberculosis and are efficacious in vivo. J Med Chem. 2013;56(23):9701-9708. doi: 10.1021/jm401382v.

22. Bobovska A, Kilacskova E, Mokos V, Svetl Z, Michal S, Kordula J. DprE1 Is a Vulnerable Tuberculosis Drug Target Due to Its Cell Wall Localization.ACS Chem.Biol. 2015; 10(7): 1631-1636. doi:10.1021/acschembio.5b00237

23. Borisov SE, Dheda K, Enwerem M, Romero Leyet R, D'Ambrosio L, Centis R, Sotgiu G, Tiberi S, Alffenaar JW, Maryandyshev A, Belilovski E, Ganatra S, Skrahina A, Akkerman O, Aleksa A, Amale R, Artsukevich J, Bruchfeld J, Caminero JA, Carpena Martinez I, Codecasa L, Dalcolmo M, Denholm J, Douglas P, Duarte R, Esmail A, Fadul M, Filippov A, Davies Forsman L, Gaga M, Garcia-Fuertes JA, García- 
García JM, Gualano G, Jonsson J, Kunst H, Lau JS, Lazaro Mastrapa B, Teran Troya JL, Manga S, Manika K, González Montaner P, Mullerpattan J, Oelofse S, Ortelli M, Palmero DJ, Palmieri F, Papalia A, Papavasileiou A, Payen MC, Pontali E, Robalo Cordeiro C, Saderi L, Sadutshang TD, Sanukevich T, Solodovnikova V, Spanevello A, Topgyal S, Toscanini F, Tramontana AR, Udwadia ZF, Viggiani P, White V, Zumla A, Migliori GB. Effectiveness and safety of bedaquiline-containing regimens in the treatment of MDR- and XDR-TB: a multicentre study. Eur Respir J. 2017;49(5):1700387. doi:10.1183/13993003.003872017

24. Borisov S, Danila E, Maryandyshev A, Dalcolmo M, Miliauskas S, Kuksa L, Manga S, Skrahina A, Diktanas S, Codecasa LR, Aleksa A, Bruchfeld J, Koleva A, Piubello A, Udwadia ZF, Akkerman OW, Belilovski E, Bernal E, Boeree MJ, Cadiñanos Loidi J, Cai Q, Cebrian Gallardo JJ, Dara M, Davidavičienė E, Forsman LD, De Los Rios J, Denholm J, Drakšienė J, Duarte R, Elamin SE, Escobar Salinas N, Ferrarese M, Filippov A, Garcia A, García-García JM, Gaudiesiute I, Gavazova B, Gayoso R, Gomez Rosso R, Gruslys V, Gualano G, Hoefsloot W, Jonsson J, Khimova E, Kunst H, Laniado-Laborín R, Li Y, Magis-Escurra C, Manfrin V, Marchese V, Martínez Robles E, Matteelli A, Mazza-Stalder J, Moschos C, Muñoz-Torrico M, Mustafa Hamdan H, Nakčerienė B, Nicod L, Nieto Marcos M, Palmero DJ, Palmieri F, Papavasileiou A, Payen MC, Pontarelli A, Quirós S, Rendon A, Saderi L, Šmite A, Solovic I, Souleymane MB, Tadolini M, van den Boom M, Vescovo M, Viggiani P, Yedilbayev A, Zablockis R, Zhurkin D, Zignol M, Visca D, Spanevello A, Caminero JA, Alffenaar JW, Tiberi S, Centis R, D'Ambrosio L, Pontali E, Sotgiu G, Migliori GB. Surveillance of adverse events in the treatment of drug-resistant tuberculosis: first global report. Eur Respir J. 2019;54(6):1901522. doi:10.1183/13993003.01522-2019

25. Kartik K and Abubakarl. Clinical implications of the global multidrug-resistant tuberculosis epidemic.ClinMed j. 2016;16(6):565-570. doi.org/10.7861/clinmedicine.16-6-565

26. Lange C, Aarnoutse RE, Alffenaar JWC, Bothamley G, Brinkmann F, Costa J, Chesov D, van Crevel R, Dedicoat M, Dominguez J, Duarte R, Grobbel HP, Günther G, Guglielmetti L, Heyckendorf J, Kay AW, Kirakosyan O, Kirk O, Koczulla RA, Kudriashov GG, Kuksa L, van Leth F, Magis-Escurra C, Mandalakas AM, Molina-Moya B, Peloquin CA, Reimann M, Rumetshofer R, Schaaf HS, Schön T, Tiberi S, Valda J, Yablonskii PK, Dheda K. Management of patients with multidrug-resistant tuberculosis. Int J Tuberc Lung Dis. 2019;23(6):645-662. doi:10.5588/ijtld.18.0622

27. Migliori GB, Tiberi S, Zumla A, Petersen E, Chakaya JM, Wejse C, Muñoz Torrico M, Duarte R, Alffenaar JW, Schaaf HS, Marais BJ, Cirillo DM, Alagna R, Rendon A, Pontali E, Piubello A, Figueroa J, Ferlazzo G, García-Basteiro A, Centis R, Visca D, D'Ambrosio L, Sotgiu G; members of the Global Tuberculosis Network. MDR/XDR-TB management of patients and contacts: Challenges facing the new decade. The 2020 clinical update by the Global Tuberculosis Network. Int J Infect Dis. 2020;92S:S15-S25. doi:10.1016/j.ijid.2020.01.042

28. Nahid P, Mase SR, Migliori GB, Sotgiu G, Bothamley GH, Brozek JL, Cattamanchi A, Cegielski JP, Chen L, Daley CL, Dalton TL, Duarte R, Fregonese F, and et al. Treatment of Drug-Resistant Tuberculosis. An 
Official ATS/CDC/ERS/IDSA Clinical Practice Guideline. Am J RespirCrit Care Med. 2019; 200(10):e93e142.

29. Gandhi NR, Shah NS, Andrews JR, et al. HIV Coinfection in Multidrug- and Extensively Drug-Resistant Tuberculosis Results in High Early Mortality. Am J RespirCrit Care Med.2010; 181: 80-86. doi:10.1164/rccm.200907-09890C

30. Shaikh MH, Subhedar DD, Nawale L, Sarkar D, Khan FA, Sangshetti JN, Shingate BB. 1, 2, 3-Triazole derivatives as antitubercular agents: synthesis, biological evaluation and molecular docking study. MedChemComm. 2015;6(6):1104-16.

31. Greenwood JR, Calkins D, Sullivan AP, Shelley JC. Towards the comprehensive, rapid, and accurate prediction of the favorable tautomeric states of drug-like molecules in aqueous solution. $\mathrm{J}$ Comput Aided Mol Des. 2010; 24:591-604. doi:10.1007/s10822-010-9349-1

32. Zumla A, Nahid P, Cole ST. Advances in the development of new tuberculosis drugs and treatment regimens. Nat Rev Drug Discov. 2013;12(5):388-404. doi:10.1038/nrd4001

33. You A, Zhou J, Song S, Zhu G, Song H, Yi W. Bioorganic \& Medicinal Chemistry Rational design, synthesis and structure - activity relationships of analogues as novel tyrosinase inhibitors. Bioorg Med Chem. 2015;23(5):924-931. doi:10.1016/j.bmc.2015.01.024

34. Madhavaram M, Tigulla P. 3D QSAR and molecular docking studies of 4-alkoxy-and 4-acyloxy phenyl ethylene thiosemicarbazone derivatives as tyrosinase inhibitors. Med Chem Res.2017; 26: 31253135. DOI 10.1007/s00044-017-2007-6

35. Madhavaram M, Nampally V, Gangadhari S, Palnati MK, Tigulla P. High-throughput virtual screening, ADME analysis, and estimation of MM/GBSA binding-free energies of azoles as potential inhibitors of Mycobacterium tuberculosis H37Rv. J Recept Signal Transduct Res. 2019;39(4):312-320. DOI:

10.1080/10799893.2019.1660895

36. Friesner RA, Banks JL, Murphy RB, Halgren TA, Klicic JJ, Mainz DT, Repasky MP, Knoll EH, Shelley M, Perry JK, Shaw DE, Francis P, Shenkin PS. Glide: a new approach for rapid, accurate docking and scoring. 1. Method and assessment of docking accuracy. J Med Chem. 2004;47(7):1739-1749. doi:10.1021/jm0306430

37. Halgren TA, Murphy RB, Friesner RA, Beard HS, Frye LL, Pollard WT, Banks JL. Glide: a new approach for rapid, accurate docking and scoring. 2. Enrichment factors in database screening. J Med Chem. 2004 Mar 25;47(7):1750-9. doi: 10.1021/jm030644s.

38. Jorgensen WL, Maxwell DS, Tirado-Rives J. Development and testing of the OPLS all-atom force field on conformational energetics and properties of organic liquids. J Am Chem Soc. 1996;118(45):1122511236. doi:10.1021/ja9621760 
39. Friesner RA, Murphy RB, Repasky MP, Frye LL, Greenwood JR, Halgren TA, Sanschagrin PC, Mainz DT. Extra precision glide: docking and scoring incorporating a model of hydrophobic enclosure for proteinligand complexes. J Med Chem. 2006;49(21):6177-6196. doi:10.1021/jm0512560

40. Madhavi Sastry G, Adzhigirey M, Tyler D, Ramakrishna A, Woody S. Protein and ligand preparation : parameters, protocols, and influence on virtual screening enrichments. J Comput Aided Mol Des. 2013; 27:221-234. doi:10.1126/science. 1171583

41. Maestro version 9.0 Schrodinger LLC NEWYORK 2010.

42. Saikiran Reddy P, SreeKanth S, Vijjulatha M. An integrated molecular modeling approach for in silico design of new tetracyclic derivatives as ALK inhibitors An integrated molecular modeling approach for in silico design of new tetracyclic derivatives as ALK inhibitors. J Recept Signal Transduct. 2016;36(5):488504. doi:10.3109/10799893.2015.1130057

43. Kaserer T, Beck KR, Akram M, Odermatt A, Schuster D, Willett P. Pharmacophore models and pharmacophore-based virtual screening: Concepts and applications exemplified on hydroxysteroid dehydrogenases. Molecules. 2015;20(12):22799-22832. doi:10.3390/molecules201219880

44. Foloppe N, Hubbard R. Towards Predictive Ligand Design With Free-Energy Based Computational Methods ?. Curr Med Chem. 2006;13(29): 3583-3608.doi: 10.2174/092986706779026165.

45. Hou T, Wang J, Li Y, Wang W. Assessing the performance of the MM/PBSA and MM/GBSA methods. 1. The accuracy of binding free energy calculations based on molecular dynamics simulations. $J$ Chemlnf Model. 2011;51(1):69-82. doi.org/10.1021/ci100275a

46. Hou T, Wang J, Li Y, Wang W. Assessing the performance of the MM/PBSA and MM/GBSA methods: II. The accuracy of ranking poses generated from docking. J Comput Chem. 2011;32(5):866-877. doi:10.1002/jcc. 21666

47. Xu L, Sun H, Li Y, Wang J, Hou T. Assessing the performance of MM/PBSA and MM/GBSA methods. 3. the impact of force fields and ligand charge models. J Phys Chem B. 2013;117(28):8408-8421. doi:10.1021/jp404160y

48. Sun H, Li Y, Shen M, Tian S, Xu L, Pan P, Guan Y, Hou T. Assessing the performance of MM/PBSA and MM/GBSA methods. 5. Improved docking performance using high solute dielectric constant MM/GBSA and MM/PBSA rescoring. Phys Chem Chem Phys. 2014;16(40):22035-22045. doi:10.1039/c4cp03179b

49. Sun H, Li Y, Tian S, Xu L, Hou T. Assessing the performance of MM/PBSA and MM/GBSA methods. 4. Accuracies of MM/PBSA and MM/GBSA methodologies evaluated by various simulation protocols using PDBbind data set. Phys Chem Chem Phys. 2014;16(31):16719-16729. doi:10.1039/c4cp01388c

50. Rondla R, Padma Rao LS, Ramatenki V, Vadija R, Mukkera T, Potlapally SR, VuruputuriU.Azolium analogues as CDK4 inhibitors: Pharmacophoremodeling, 3D QSAR study and new lead drug 
51. Chatterji M, Shandil R, Manjunatha MR, Solapure S, Ramachandran V, Kumar N, Saralaya R, Panduga V, Reddy J, Prabhakar KR, Sharma S, Sadler C, Cooper CB, Mdluli K, lyer PS, Narayanan S, Shirude PS. 1,4azaindole, a potential drug candidate for treatment of tuberculosis. Antimicrob Agents Chemother. 2014;58(9):5325-5331. doi:10.1128/AAC.03233-14

52. Batt SM, Jabeen T, Bhowruth V, Quill L, Lund PA, Eggeling L, Alderwick LJ, Fütterer K, Besra GS. Structural basis of inhibition of Mycobacterium tuberculosis DprE1 by benzothiazinone inhibitors. Proc Natl Acad Sci U S A. 2012;109(28):11354-11359. doi: 10.1073/pnas.1205735109

53. Irwin JJ, Sterling T, Mysinger MM, Bolstad ES, Coleman RG. ZINC: a free tool to discover chemistry for biology. J Chem Inf Model. 2012;52(7):1757-68.doi: 10.1021/ci3001277.

54. Lipinski CA, Lombardo F, Dominy BW, Feeney PJ. Experimental and computational approaches to estimate solubility and permeability in drug discovery and development settings. Adv Drug Deliv Rev. 2001;46(1-3):3-26.doi: 10.1016/s0169-409x(00)00129-0.

\section{Figures}

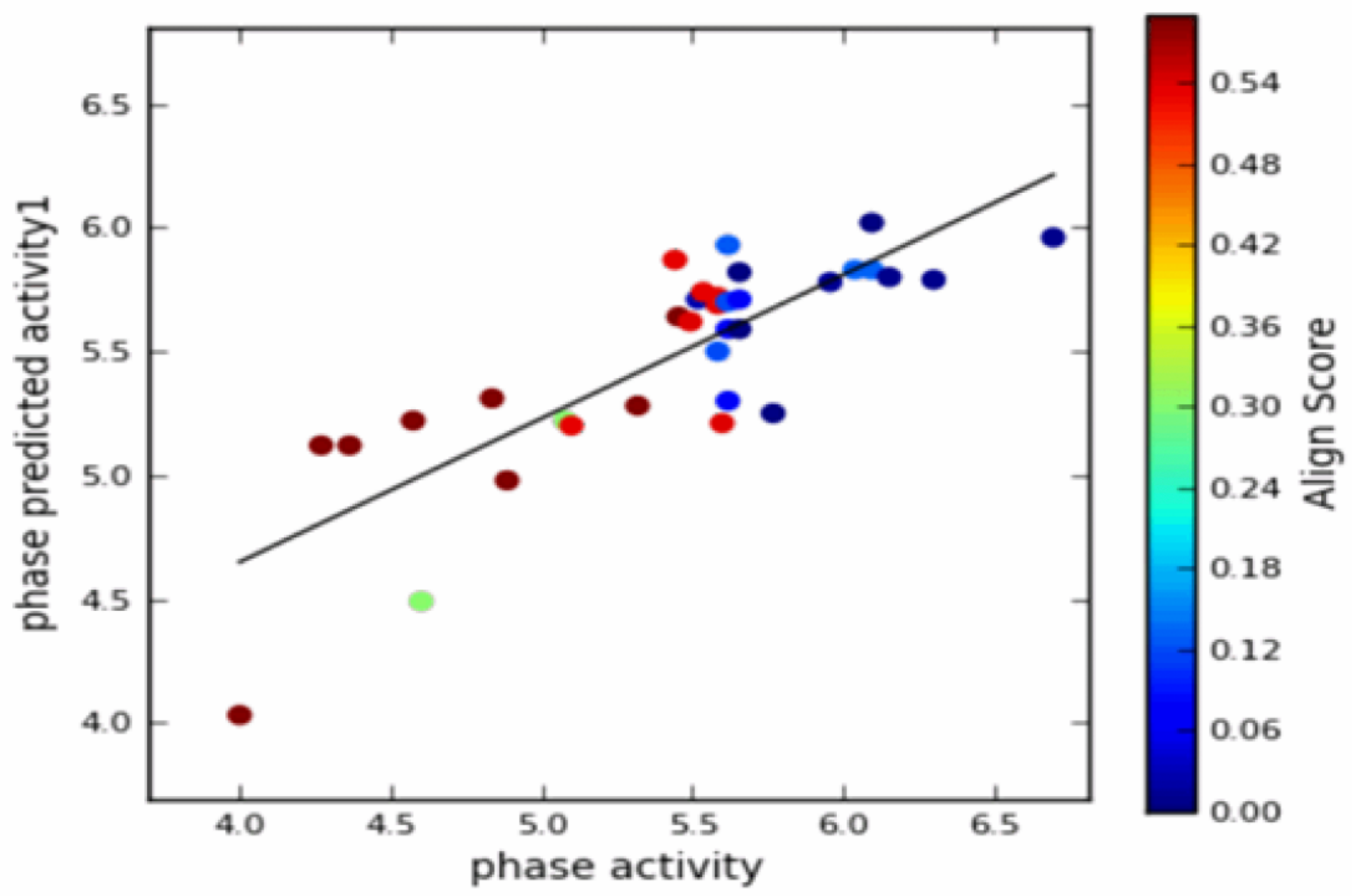




\section{Figure 1}

A correlation graph of experimental vs. predicted biological activity of both training and test set molecules.

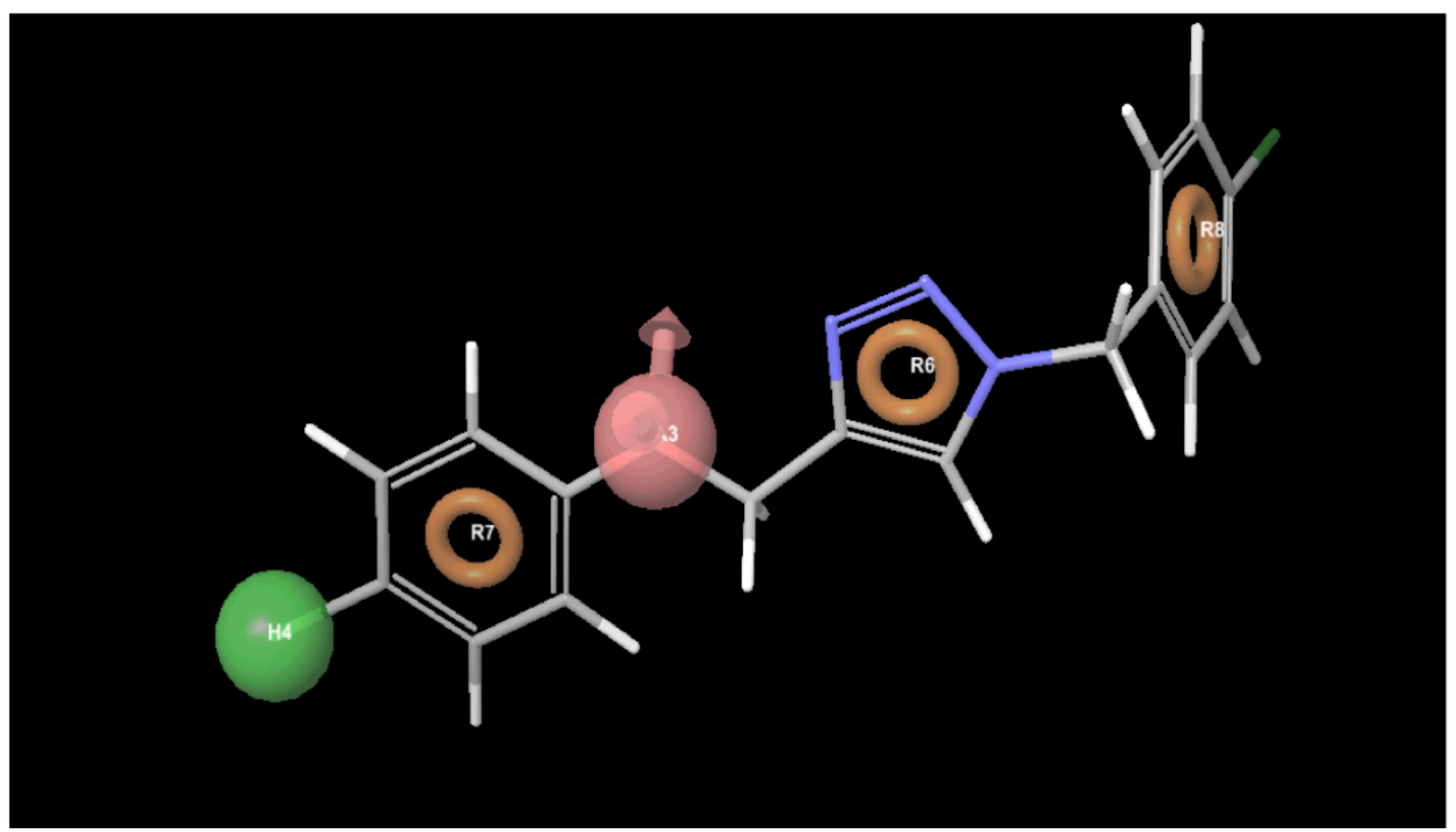

\section{Figure 2}

Alignment of best fit molecule with pharmacophoric features, where $A$ is acceptor; $H$ is hydrophobic; $R$ is aromatic ring. 


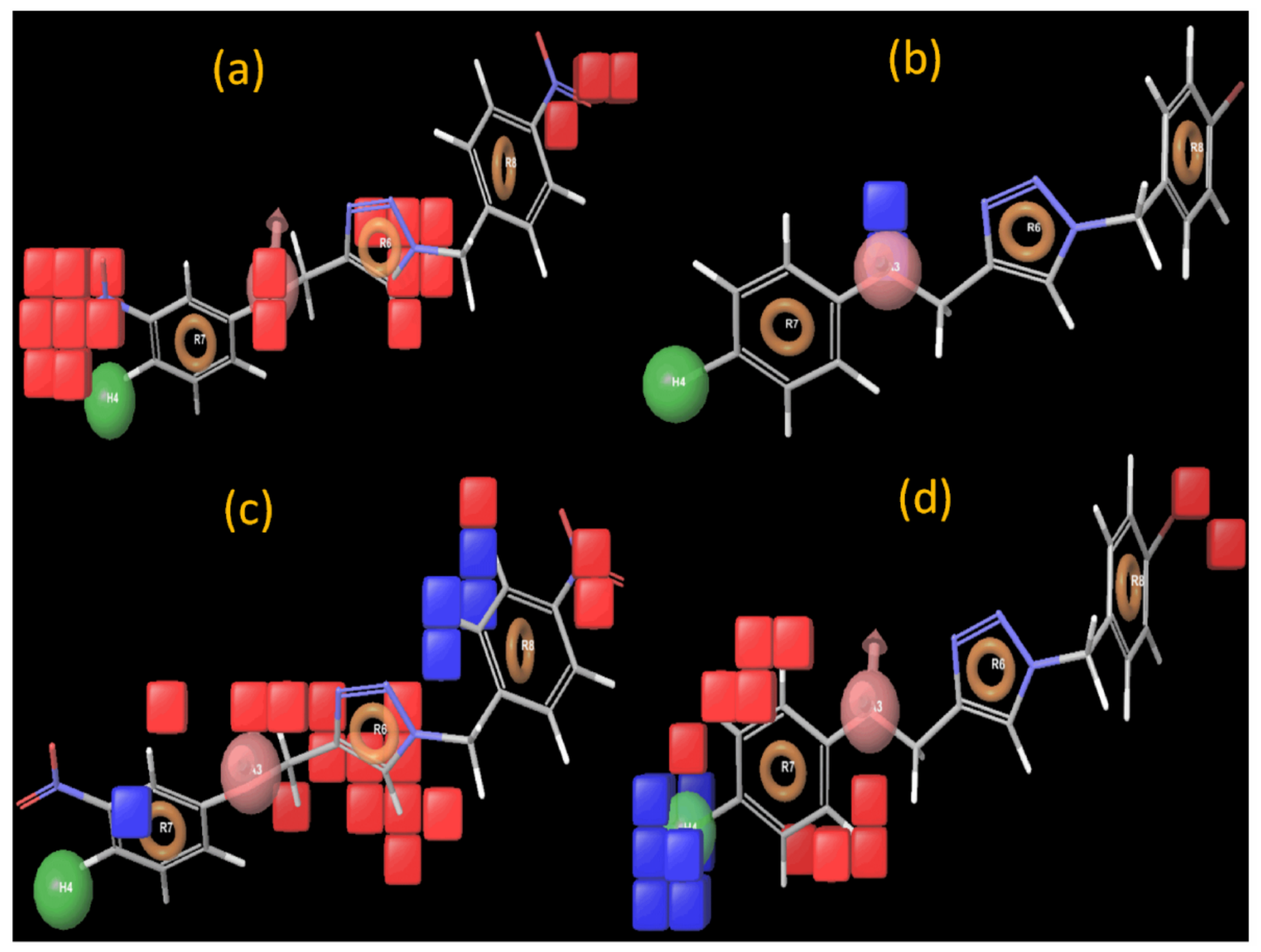

Figure 3

QSAR model visualization of inactive (M16) and active (M15) molecule (Presence of blue color cubes depicts positive potential and red color cubes depicts negative potential). (a) Visualization of electron withdrawing feature of molecule-M16. (b) Visualization of electron withdrawing feature of molecule-M15. (c) Visualization of hydrophobic feature of molecule - M16. (d) Visualization of hydrophobic feature of molecule - M15. 


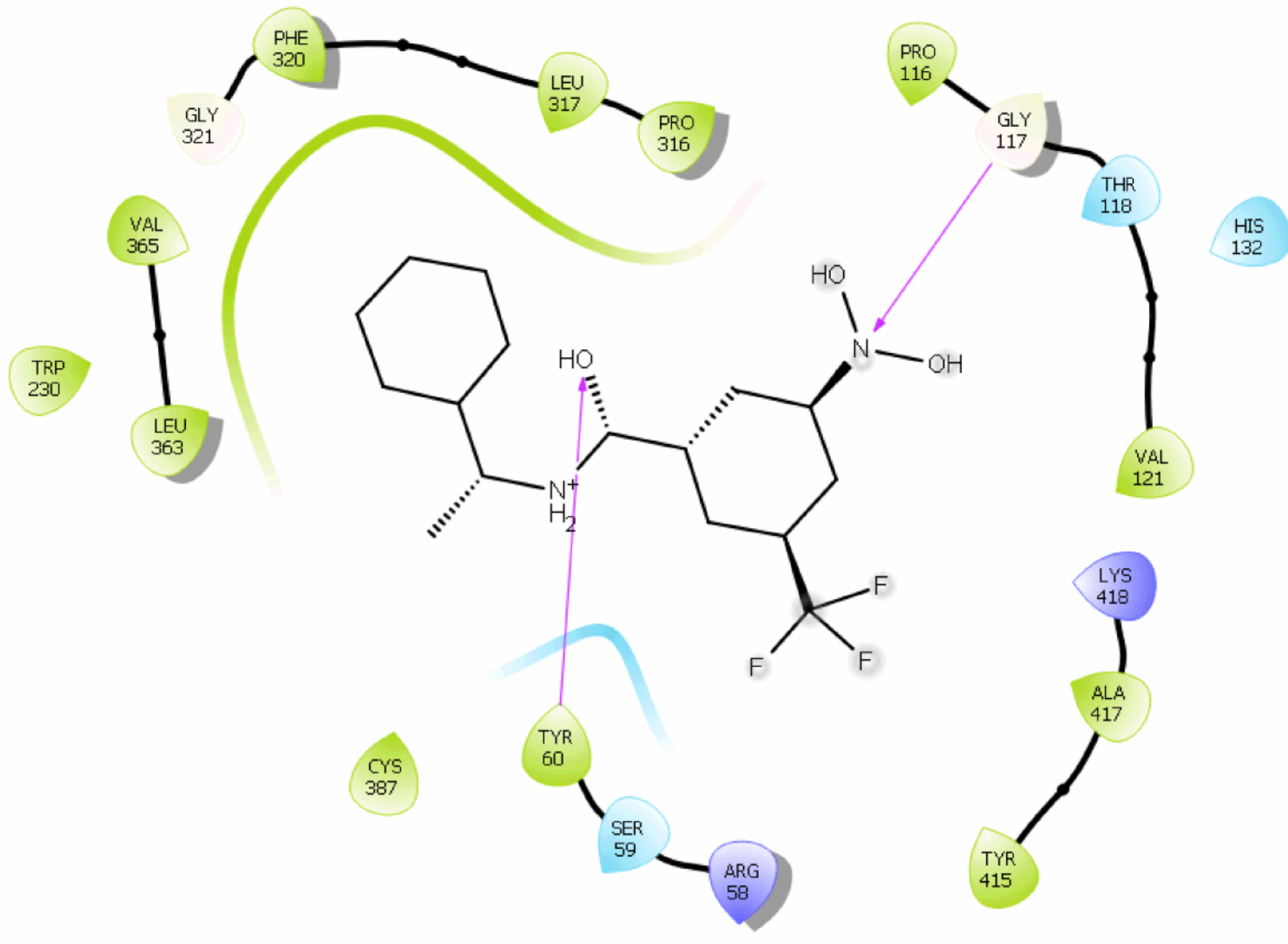

Figure 4

The residues present at active site of protein (Tyr60, Val121, Lys417, Gly117, Thr118, Pro116, Gly321, Arg58, Ser59 and Cys387). 


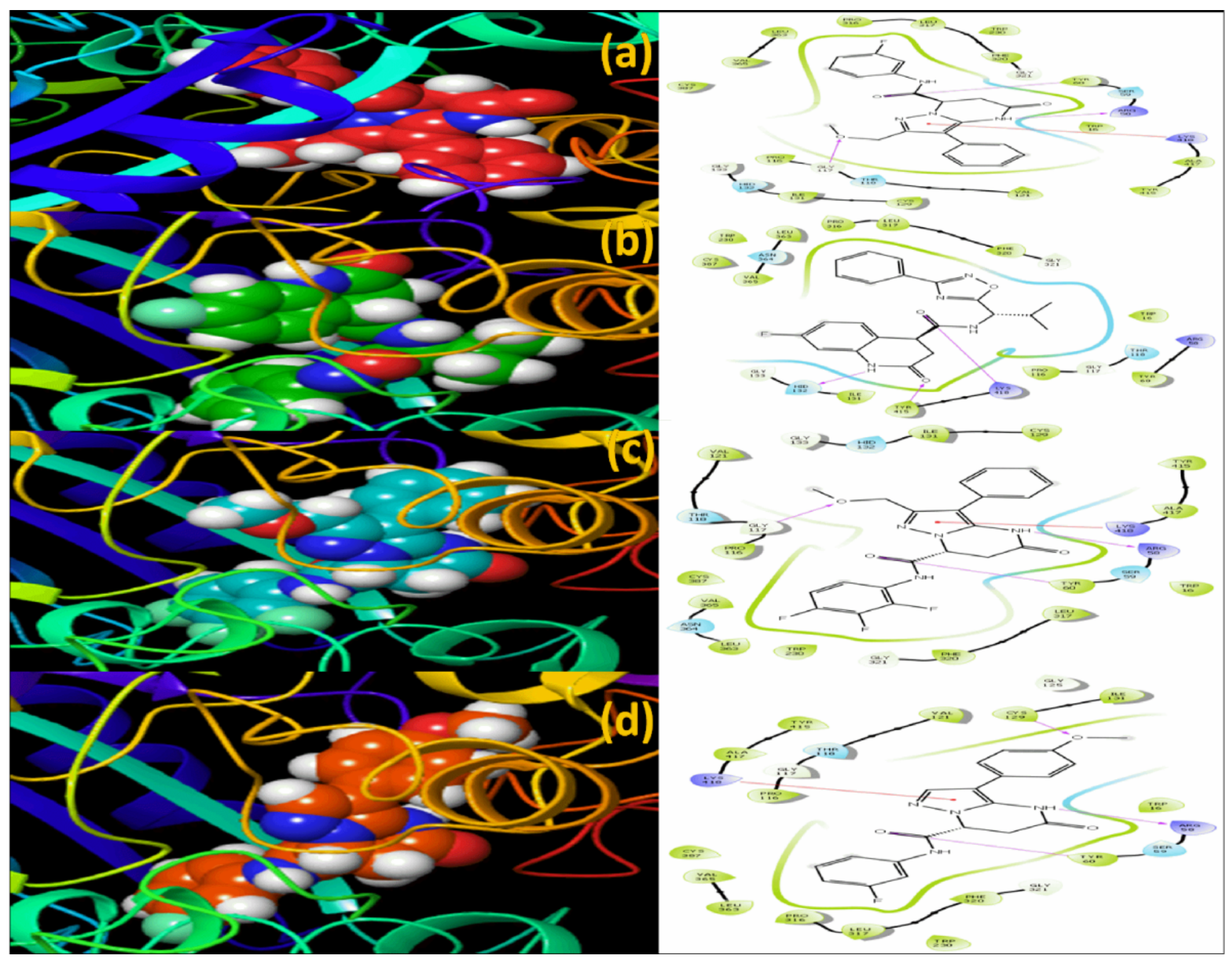

Figure 5

(a) Binding mode analysis of molecule S8 (ZINC44890235), (b) Binding mode analysis of molecule S9 (ZINC58156954), (c) Binding mode analysis of molecule S10 (ZINC44920132), (d) Binding mode analysis of molecule S14 (ZINC35685029). The violet color bonds indicates $\mathrm{H}$-bonds, red color bonds indicates that Pi-Pi staking interactions. 


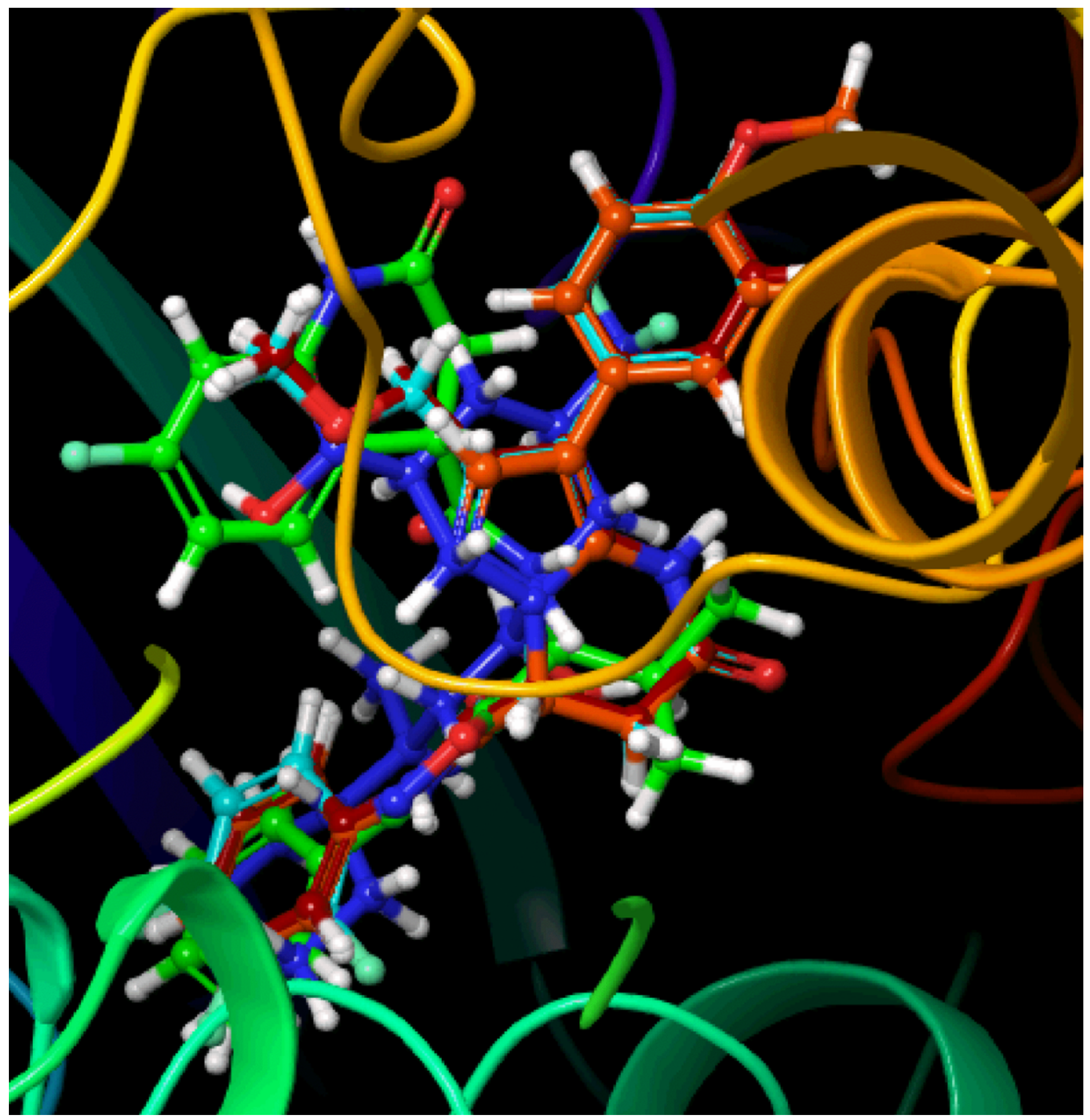

Figure 6

Binding mode analysis of all four hit molecules along with co-crystal ligand (blue).

\section{Supplementary Files}

This is a list of supplementary files associated with this preprint. Click to download. 
- Table4.docx

- suplementarydata.docx 